\title{
Growth hormone and sport: abuse, potential benefits, and difficulties in detection
}

Since the early Grecian Olympics, athletes have sought real and imaginary agents in the hope of improving performance.

Today the International Olympic Committee (IOC) use the term "doping" to describe substances whose use is prohibited in sport and have stated that it is their policy to prevent the use of those drugs that constitute dangers when misused. Most international federations follow the doping rules laid down by the IOC.

Growth hormone (GH) is a peptide hormone. Produced naturally by the pituitary gland, $\mathrm{GH}$ is a single chain peptide of 191 amino acids stabilised by two disulphide bridges, with a molecular weight of approximately 22000 Daltons. GH is a potent agent needed for normal growth in childhood, and having numerous recently discovered effects in adulthood, including stimulation of anabolism and lipolysis, increases in red cell mass, cardiac function, and various complex actions on carbohydrate metabolism. $^{12}$

Its anabolic properties, together with difficulties in its detection by current doping procedures, lend it a high potential for abuse. There are, however, some potential problems for the abuser. The only form of $\mathrm{GH}$ active in the human is human (or primate) GH. This contrasts with insulin in which animal insulins are equipotent, and thus easier and cheaper to produce. $\mathrm{GH}$ has however recently become available biosynthetically in unlimited quantities through advances in biotechnology, and recombinant human $\mathrm{GH}(\mathrm{r}-\mathrm{hGH})$, produced by recombinant DNA technology, has an amino acid sequence identical to the pituitary derived one.

Although hard facts are difficult to obtain, every indication is that its use in sport is on the increase. Contraband hauls by customs officials have on occasions, contained substantial quantities of GH. Some of this has originated in countries where GH of human origin is still available, and thus is liable to be infected with the Creutzfeldt-Jakob prion. A number of burglaries from pharmacies seemed to have focused on obtaining GH. Several athletes have con-

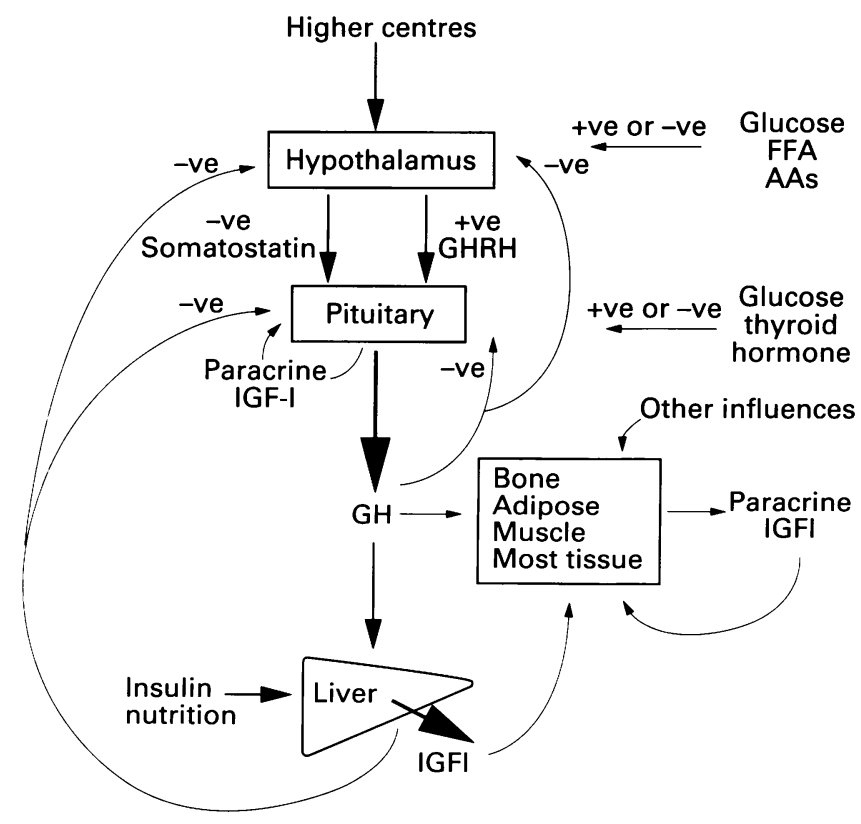

Figure 1 Schematic diagram of the GH/IGF1 axis. fessed to $\mathrm{GH}$ abuse and it has been given a powerful write up in "The Underground Steroid Handbook".

To understand the potential benefit of $\mathrm{GH}$ to the athlete it is important to be aware that $\mathrm{GH}$ is now known to have major beneficial effects in adult humans. $\mathrm{GH}$ replacement in adults who are deficient in its production leads to increased muscle mass and strength, increased cardiac performance and mass, increased red cell mass, circulatory volume and oxygen carriage. ${ }^{3}$ All contribute to an improved exercise performance. There are also reductions in body fat, serum lipids, and an improved sense of psychological well being. ${ }^{4}$

GH is produced throughout adult life, with highest values during puberty. It is secreted in discreet pulses (6-8 per day) with an almost undetectable concentration in plasma between pulses. Apart from its inherent pulsatility, other important stimulatory factors include exercise, sleep, fasting, protein ingestion, hypoglycaemia, pregnancy, and psychological stress. Factors known to surpress endogenous GH production include: obesity, carbohydrate ingestion, and high serum free fatty acid concentrations.

At a central level, GH release is under stimulatory and inhibitory control of the hypothalamic peptide growth hormone releasing factor (GRF) and somatostatin respectively (fig 1).

Both $\alpha 2$ and $\alpha 1$ adrenergic stimulation are believed to evoke GH increments via augmentation of GRF release, while $\beta$ adrenergic stimulation increases somatostatin release. ${ }^{5} \mathrm{GH}$ circulates in association with $\mathrm{GH}$ binding proteins (GH-BP), and its receptors occur in a wide variety of tissues. Hepatic $\mathrm{GH}$ receptors mediate the production of insulin-like growth factor 1 (IGF1), which has potent anabolic activity, effecting many of the anabolic actions of GH. ${ }^{6}$ There have been several controlled studies to examine the effects of administering supraphysiological doses of GH to highly trained athletes. ${ }^{78}$ Overall these studies suggest that such doses may cause very small increases in lean tissue mass and reductions in fat mass.

Skeletal muscle hypertrophy has not been shown, and muscle strength is not increased despite anecdotal reports of performance enhancement.

As the efficiency of detection of steroids increases, the value of $\mathrm{GH}$ as a non-detectable doping agent becomes still more important. As an endogenous substance, $\mathrm{GH}$ is necessarily more difficult to detect, and biosynthetic $\mathrm{GH}$ has an amino acid sequence identical to pituitary GH. Its pulsatile secretion, short half life of about 20 minutes, and its sensitivity to positive and negative regulatory influences add to the difficulties. However, $\mathrm{GH}$ does have wide reaching metabolic effects, many of which have still not been fully elucidated, and this results in the change of various substances within the bloodstream, which have a longer plasma half life than $\mathrm{GH}$ and may prove to be useful in the detection of exogenous $\mathrm{GH}$ abuse. However, endogenous $\mathrm{GH}$ release is stimulated by a variety of physiological circumstances such as time of day, sleep, age, nutrition, and exercise. It stands to reason that potential markers of $\mathrm{GH}$ abuse may also be influenced by these factors. Athletes are known to show different responses of their $\mathrm{GH}$ axis to exercise than non-athletes.

To determine a method for the detection of $\mathrm{GH}$ abuse it is crucial therefore that we gain a full understanding of the "normal" physiology of GH in the athlete. Prolonged GH 
abuse would result in a syndrome similar to acromegaly with attendant risks of hypertension, cardiomyopathy, malignancy, myopathy, peripheral neuropathy, and glucose intolerance. Thus while $\mathrm{GH}$ at physiological levels has major beneficial effects, its abuse leaves the athlete at high risk, and it behoves the medical and scientific communities to curtail its use as a doping agent.

MARIE-LOUISE HEALY D RUSSELL-JONES

Department of Endocrinology, Diabetes and Metabolic Medicine, UMDS St Thomas's Hospital,

Lambeth Place Road, London SE1 7EH

Marie-Louise Healy is a research fellow at St Thomas's Hospital working on the $\mathrm{GH}-2000$ project, funded by the International Olympic Committe and the European Commission. There is collaboration between four clinical academic centres, all of which have expertise in peptide hormone research. The members of the partnership are Professor Bengt-Ake Bengtsson (Sweden), Professor Jens S Christiansen (Denmark), Dr J Powrie (UK), Dr David Russell-Jones (UK), Professor Luigi Sacca (Italy), and Professor Peter Sönksen (UK), the project coordinator.
The project aims at developing a methodology for the detection of the use and abuse of exogenously administered growth hormone and related substances in sport. The target is to establish this before the Sydney Olympic Games.

1 Cuneo RC, Salomon F, Wiles CM, Hesp R, Sonksen PH. Growth hormone treatment in growth-hormone deficient adults. I. Effects on skeletal muscle mass and strength. $f$ Appl Physiol 1991;70:688-94.

2 Salomon F, Cuneo C, Hesp R, Sonksen PH. The effects of treatment with recombinant human growth hormone on body composition and metabolism in adults with growth hormone deficiency. $N$ Engl $\mathcal{f} \mathrm{Med}$ lism in adults with

3 Christ E, Cummings MH, Westwood NB, Sawyer B M, Pearson TC, Sonksen $\mathrm{PH}$, et al. The importance of growth hormone in the regulation of erythropoiesis, red cell mass, and plasma volume in adults with growth hormone deficiency. $\mathcal{f}$ Clin Endocrinol Metab 1997;82:8.

4 Cuneo RC, Salomon F, McGauley GA, Sonksen PH. The growth hormone deficiency syndrome in adults. Clin Endocrinol 1992:37:387-97.

$5 \mathrm{Al}$-Dalmuji S. Adrenergic control of the secretion of anterior pituitary hormones. F Clin Endocrinol Metab 1993;7:355-92.

6 Russell-Jones DL, Umpleby AM, Hennessy TR, Bowes SB, Shjaee-Moadie $\mathrm{F}$, Hopkins KD, et al. Use of aleucine clamp to demonstrate that IGF-1 actively stimulates protein synthesis in normal humans. American fournal of Physiology 1994; E591-8.

7 Crist DM, Peake GT, Egan PA, Waters DL. Body composition response to Crist DM, Peake GT, Egan PA, Waters DL. Body composition response to exogenous GH duri

8 Yarasheki KE, Campbell JA, Smith K, Rennie MJ, Holloszy JO, Bier DM. Effect of growth hormone and resistance exercise on muscle growth in young men. Am $\mathcal{F}$ Physiol Endocrinol Metab 1992;262:E261-7. Reviews

\section{A hundred years ago}

One hundred years ago, William Gilbert Grace still dominated the world of cricket. During the 1897 season, not far short of his 50th birthday, he scored 1532 runs at an average of just under 40 per innings and took 56 wickets. For any county cricketer this was a thoroughly efficient performance but, in well established middle age and nudging 19 stone on the scales, this was, apart from anything else, a remarkable demonstration of stamina. Remember that in those days there were few cars and travel around the country was mainly by rail. Fortunately, such was WG's fame that when he was late trains were often delayed until the great man arrived. Mindful of his professional commitments he continued to work in his family practice in Bristol at weekends and between matches (fig 1).

For a man of his size, perhaps not huge by today's standards, he certainly imposed formidable punish ment on his muscular skeletal system. Yet, surprisingly, during the long summer of 1897 there were no records of his sustaining any serious injuries. Mercifully he did not have to undertake regular overseas tours in the winters; his major sporting activity then was beagling. Think of the stress fractures, torn muscles, and ruptured ligaments that our own modern "all the year round" cricketers suffer. They rarely survive the first class game after their mid 30s. Perhaps the demands of professional sport neglect the need for rest and recuperation during the close season.

P J TOGHILL

Director of Continuing Medical Education

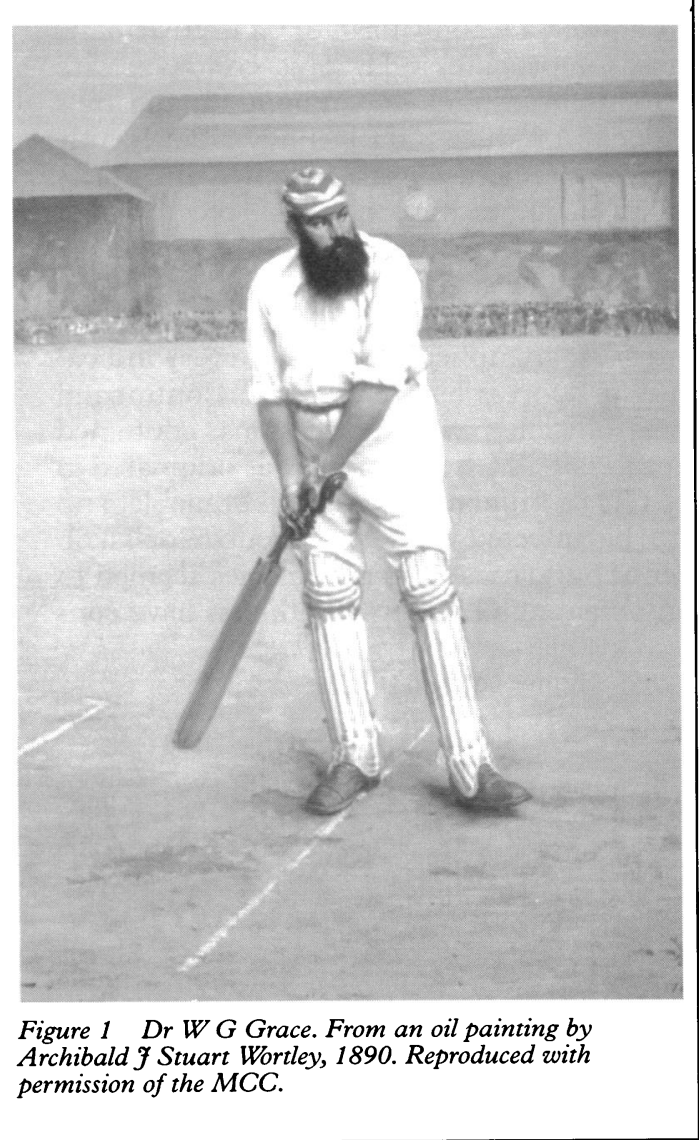

